\begin{tabular}{l|lll}
\hline History Article & Received: Januari 2020 & Approved: Februari 2020 & Published: Februari 2021 \\
\hline
\end{tabular}

\title{
PENGARUH PENAMBAHAN LIMBAH DIAPERS PADA MEDIA TANAM TERHADAP PERTUMBUHAN BAWANG DAUN SEBAGAI SUMBER BELAJAR BIOLOGI MATERI PERTUMBUHAN DAN PERKEMBANGAN
}

\author{
In Rohwadi ${ }^{1}$, Muhfahroyin ${ }^{2}$, Hening Widowati ${ }^{3}$ \\ ${ }^{1}$ SMA Muhammadiyah 1 Pekalongan Lampung Timur ${ }^{2,3}$ Universitas Muhammadiyah Metro \\ Email: ${ }^{1}$ inrohwadi0107@gmail.com, ${ }^{2}$ muhfahroyin@yahoo.com, $\underline{3}$ hwummetro@gmail.com
}

\begin{abstract}
Abstrak: Limbah diapers terdapat urin yang mengandung unsur nitrogen mampu meningkatkan pertumbuhan tanaman. Penelitian ini bertujuan untuk mengetahui pengaruh penambahan limbah diaperspada media tanam terhadap pertumbuhan tanaman bawang daun (Allium fistulosum. L) sebagai sumber belajar biologi dalam penyusunan brosur edukasi materi Pertumbuhan dan Perkembangan. Penelitian ini menggunakan Rancangan Acak Lengkap (RAL) dengan 1 kontrol dan 3 perlakuan dengan 8 kali pengulangan. Penelitian ini dilakukan selama 5 minggu.Parameter yang digunakan dalam penelitian ini meliputi tinggi tanaman, diameter batang semu dan helaian daun bawang (Allium fistulosum. L), dengan data pendukung dianalisis menggunakan aplikasi SPSS 25.0 yang meliputi One Way ANOVA. Hasil dari penelitian ini dapat disimpulkan bahwa penambahan limbah diapers pada media tanam berpengaruh terhadap pertumbuhan tanaman bawang daun. Hasil peneltian ini dapat dijadikan sebagai sumber belajar berupa Brosur edukasi materi Pertumbuhan dan Perkembangan. Penelitian ini masih terbatas dalam menemukan referensi tentang pemanfaatan limbah diapers sebagai media tanam. Sumber belajar berupa brosur hendaknya dapat dimanfaatkan sebagai sumber informasi.

Kata Kunci: Allium fistulosumL, limbah diapers, media tanam, sumber belajar.
\end{abstract}

\begin{abstract}
Diapers waste contains urine which contains nitrogen which can increase plant growth. This research was aimed at investigating the effect of adding the diapers waste on the growing media towards the growth of leeks (Allium fistulosum. L), in further, it would be used as the learning source of Biological insight to have a particular form of educational brochure in case of growth and development. This research used a completely randomized design (CRD) with 1 control and 3 treatments with 8 repetitions. This research was conducted for 5 weeks. The parameters used in this study included plant height, pseudo stem diameter and chives (Allium fistulosum. L) with supporting data analyzed using the SPSS 25.0 application which includes One Way ANOVA. The results of this research concluded that the addition of diapers waste to the growing media had an effect on the growth of leek plants. The results of this research can be used as a learning resource in the form of educational brochures on growth and development materials. This research is still limited in finding references on the use of diapers waste as a planting medium. Finally, the educational brochure as the product of this present study was expected to give some advantages for the students both theoretically and practically.
\end{abstract}

Keywords :Allium fistulosum. L, diapers waste, growing media, learning source.

\section{How to Cite}

Rohwadi, In, Muhfahroyin, dan Hening Widowati. 2021. Pengaruh Penambahan Limbah Diapers Pada Media Tanam Terhadap Pertumbuhan Bawang Daun Sebagai Sumber Belajar Biologi Materi Pertumbuhan Dan Perkembangan. Biolova 2(1). 72-.78 
Bawang daun termasuk tanaman setahun atau semusim yang berbentuk rumput. Sistem perakarannya termasuk akar serabut yang terpencar kesemua arah pada kedalaman antar 15-30 cm. Bagian batang semu yang tertimbun tanah umumnya berwarna keputihputihan.Bentuk daun dari bawang daun yaitu bulat panjang yang didalamnya berlubang seperti pipa, kadang-kadang dapat membentuk umbi ukuran kecil.Warna daun pada umumnya hijau muda sampai hijau tua (Cahyono, 2005).

Konsumen bawang daun semakin meningkat mengakibatkan petani bawang daun menggunakan pupuk kimia secara berlebihan.Pupuk kimia tersebut diantaranya NPK, $\mathrm{KCl}$, SP dan Urea.Pemakaian pupuk kimia yang relatif tinggi dan secara terus menerus akan berdampak negatif pada lingkungan biologis tanah. Pemakaian pupuk kimia yang terus menerus menyebabkan Ekosistem Biologis tanah menjadi tidak seimbang (Sutanto, 2006).Solusi yang tepat untuk mengatasi hal tersebut adalah pengalihan penggunaan pupuk kimia dengan pupuk organik.

Disposable diapers atau popok sekali pakai yang telah digunakan oleh masyarakat di sekitar pemukiman warga. Sehingga diapers pasca pakai menimbulkan pencemaran lingkungan baik pencemaaran air, pencemaran tanah, dan pencemaran udara. Disposable diapers atau diapers mengandung hydrogel yaitu gel yang dapat menyerap air dan menyimpan air. Selain hidrogel pada popok bayi atau diapers memiliki kandungan lain dari limbah tersebut yaitu urin pada manusia.

Urin terdiri dari air dengan bahan terlarut berupa sisa metabolisme (seperti urea), garam terlarut, dan materi organik. Cairan yang tersisa mengandung urea dalam kadar yang tinggi dan berbagai senyawa yang berlebih atau berpotensi racun yang akan dibuang keluar tubuh (Wikipedia, 2013).

Urin manusia mengandung 15$19 \% \mathrm{~N}, 1-2 \% \mathrm{P}$ dan $3-5 \% \mathrm{~K}$, sehingga urin juga berpotensi sebagai pupuk organik cair yang berguna bagi pertumbuhan tanaman (Soeparman, 2002). Maka dari itu kandungan urine pada limbah diapers ini bisa juga digunakan sebagai pupuk setelah dilakukan fermentasi untuk mengurai senyawa-senyawa organiknya.

Pengolahan limbah diapers diperlukan adanya bakteri yang dapat mengikat unsur makro seperti nitrogen, fosfor dan kalium yaitu dengan menggunakan pupuk Pumakkal. Pumakkal merupakan pupuk organik multifungsi berbasis potensi lokal dan salah satu temuannya adalah bakteri indigen Limbah Cair Nanas (LCN).

Sutanto (2010:23) menyatakan bahwa, limbah nanas terdapat isolat yang mampu menguraikan bahan organik melalui proses bioremediasi. Proses ini akan menaikkan $\mathrm{pH}$ dan menguraikan bahan organik yang banyak terkandung dalam limbah nanas. Akhir proses ini menghasilkan bahan akhir berupa $\mathrm{CO}_{2}$ dan $\mathrm{H}_{2} \mathrm{O}$ yang aman bagi lingkungan perairan.

Dalam pembuatan pupuk organik bakteri Limbah Cair Nanas (LCN) berperan sebagai aktivator sehingga sangat berperan penting dalam proses fermentasi. Di dalam LCN Pumakkal juga terdapat unsurunsur yang dibutuhkan oleh tanaman diantaranya $\mathrm{C}, \mathrm{N}, \mathrm{P}, \mathrm{K}, \mathrm{Ca}, \mathrm{Mg}, \mathrm{Na}, \mathrm{Fe}$, $\mathrm{Zn}, \mathrm{Mn}, \mathrm{S}, \mathrm{NO}_{3}, \mathrm{NH}_{4}$, dan $\mathrm{C} / \mathrm{N}$.

Penelitian ini diharapkan mampu menjadi sumber belajar yang praktis dan menarik sehingga dapatmeningkatkan minat baca siswa terutama pada materi Pertumbuhan dan Perkembangan Tanaman.

Menurut

Muhfahroyin (2009:25) dan Juhri (2013:60) dapat 
diuraikan, bahwa sumber belajar mempunyai peranan yang sangat penting dan sangat erat dengan pembelajaran yang dilakukan dengan jalan mengadakan interaksi antara siswa dengan objek dan sumber belajar sesuai dengan uraian materi pembelajaran yang telah dirumuskan.

Sumber belajar yang dimaksud dapat disusun dalam bentuk media cetak bergambar yang menarik, salah satunya yaitu Brosur. Menurut Sadiman (2008), gambar-gambar yang dituangkan dalam bahan ajar berupa brosur akan memudahkan siswa untuk memahami materi yang disajikan lebih jelas dibandingkan hanya menggunakan bahasa verbal.

Menurut bentuknya bahan ajar dibedakan menjadi empat macam, yaitu: (a) bahan cetak (printed), contohnya handout, buku, modul, LKS, brosur dan lain-lain; (b) bahan ajar dengar atau program audio, yaitu semua sistem yang menggunakan sinyal radio secara langsung dan dapat dimainkan serta didengar oleh penggunanya; (c) bahan ajar audiovisual, contohnya film dan VCD; (d) bahan ajar interaktif, yaitu kombinasi dua atau lebih media yang diberikan perlakuan untuk menjalankan suatu perintah (Prastowo, 2014).

Tujuan dari penelitian ini adalah untuk mengetahui pengaruh penambahan limbah diapers pada media tanam terhadap pertumbuhan tanaman bawang daun (Allium fistulosum. L) sebagai sumber belajar biologi dalam penyusunan brosur edukasi materi pertumbuhan dan perkembangan.

\section{METODE}

Penelitian ini merupakan penelitian eksperimen yang dilaksanakan selama 5 minggu di Desa Sidodadi Kecamatan Pekalongan, Lampung Timur dari tanggal 1 Juni
2020 sampai dengan 5 Juli 2020. Penelitian menggunakan tanaman bawang daun berumur 1 bulan penanaman dari masa penyemaian. Limbah diapers diperoleh dari warga sekitar. Limbah diapers diolah dengan cara mengambil gel yang ada didalamnya lalu menambahkan LCN Pumakkal kemudian didiamkan selama 3 hari.

Tanah humus yang dipakai sebagai media tanam merupakan tanah yang sudah bercampur dengan berbagai kotoran hewan dan daun-daun yang sudah membusuk. Alat yang diperlukan diantaranya cangkul, ember, polybag berukuran $15 \times 25 \mathrm{~cm}$, penggaris, benang, waring, sarung tangan, masker, alat tulis dan label.

Penelitian ini menggunakan teknik Rancangan Acak Lengkap (RAL) dengan 3 kali perlakuan P1, P2 dan P3 serta 1 kontrol P0. Penelitian dilakukan dengan 8 kali pengulangan dengan total tanaman 32 buah. Masingmasing komposisi perlakuan adalah: $\mathrm{P} 0=1000 \mathrm{~g}$ tanah humus murni, $\mathrm{P} 1=$ $250 \mathrm{~g}$ atau $1 / 4 \mathrm{~kg}$ limbah diapers ditambahkan ke dalam $750 \mathrm{~g}$ atau $3 / 4 \mathrm{~kg}$ tanah humus, $\mathrm{P} 2=500 \mathrm{~g}$ atau $1 / 2 \mathrm{~kg}$ limbah diapers ditambahkan ke dalam $1 / 2 \mathrm{~kg}$ atau $500 \mathrm{~g}$ tanah humus, $\mathrm{P} 3=750$ $\mathrm{g}$ atau $3 / 4 \quad \mathrm{~kg}$ limbah diapers ditambahkan ke dalam $250 \mathrm{~g}$ atau $1 / 4 \mathrm{~kg}$ tanah humus. Masing masing komposisi dimasukkan ke dalam polybag, lalu ditambahkan tanaman bawang daun. Selanjutnya diletakkan di area yang terkena sinar matahari langsung.

Analisis data dalam penelitian ini menggunakan ANAVA satu arah untuk mengetahui ada tidaknya pengaruh penambahan limbah diapers pada media tanam.

Hasil penelitian ini disusun menjadi sumber belajar biologi dalam bentuk media cetak yaitu brosur edukasi untuk menunjang materi pertumbuhan dan perkembangan. 
Brosur iniselanjutnya divalidasi oleh dosen tim ahli yang meliputi aspek materi dan aspek desain.

Menurut Kristianingrum (2007), produk sumber belajar brosur edukasidapat dikatakan valid apabila pada skor angket yang diperoleh didapatkan hasil yang berada pada rentang $81 \% \leq$ skor $\leq 100 \%$ dan $61 \% \leq$ skor $\leq 80 \%$ atau pada kriteria "Sangat Baik", dan "Baik".

\section{HASIL DAN PEMBAHASAN Tinggi Tanaman}

Data rata-rata tinggi tanaman bawang daun minggu kelima dengan 3 perlakuan dan 1 kontrol dapat dilihat pada gambar 1 diagram rata-rata tinggi bawang daun di bawah ini.

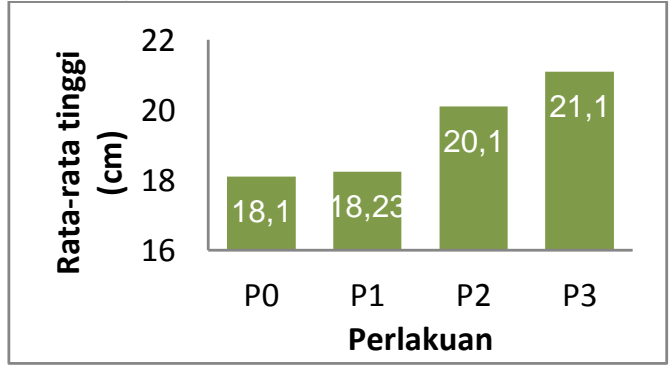

Gambar 1.Diagram Rata-rata Tinggi Tanaman Bawang Daun Minggu Ke 5

Pertumbuhan tinggi tanaman yang paling besar yaitu pada perlakuan P3 (750 g limbah diapers atau $3 / 4 \mathrm{~kg}+250$ $\mathrm{g}$ tanah humus per polybag), dengan rata-rata $21,1 \mathrm{~cm}$, serta pertumbuhan tinggi terendah yaitu pada perlakuan kontrol P0 (1000 g tanah humus tanpa penambahan limbah diapers) dengan rata-rata $18,1 \mathrm{~cm}$. Dari tabel di atas dapat diketahui bahwa penambahan limbah diapers ke dalam media tanam tanah humus berpengaruh terhadap pertumbuhan tinggi tanaman bawang daun. Hal tersebut dapat diketahui dari hasil uji ANAVA satu arah menunjukkan bahwa nilai sig. 0,002 < 0,05 .

\section{Diameter Batang Semu Tanaman}

Data rata-rata diameter batang semu tanaman bawang daun minggu ke 5 dengan 3 perlakuan dan 1 kontrol dapat dilihat pada gambar diagram rata-rata diameter batang semu bawang daun di bawah ini.

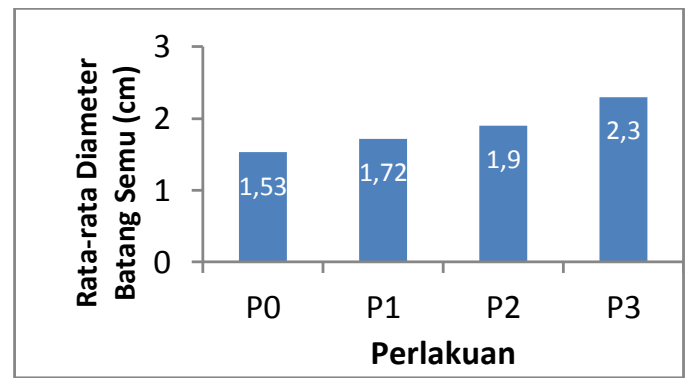

Gambar 2.Diagram Rata-rata Diameter Batang Semu Tanaman Bawang Daun Pada MingguKe 5

Rata-rata diameter batang semu tanaman yang paling besar yaitu pada perlakuan P3 (750 g limbah diapers atau $3 / 4 \mathrm{~kg}+$ tanah humus per polybag), dengan rata-rata $2,3 \mathrm{~cm}$, serta diameter batang terendah yaitu pada perlakuan kontrol P0 (1000 g tanah humus tanpa penambahan limbah diapers) dengan rata-rata $1,53 \mathrm{~cm}$. Gambar diagram di atas menunjukkan adanya pengaruh penambahan limbah diapers terhadap pertumbuhan diameter batang semu tanama bawang daun.Hal tersebut dapat diketahui dari hasil uji ANAVA satu arah menunjukkan bahwa nilai sig. $0,001<0,05$

\section{Jumlah Helaian Daun Tanaman}

Rata-rata jumlah helaian daun tanaman bawang daun yang paling baik yaitu pada perlakuan P3 (750 g limbah diapers atau $3 / 4 \mathrm{~kg}+$ tanah humus per polybag), dengan rata-rata $4,22 \mathrm{~cm}$.

Sedangkan jumlah helaian daun terendah yaitu pada perlakuan kontrol P0 (1000 g tanah humus tanpa penambahan limbah diapers) dengan rata-rata $3,27 \mathrm{~cm}$. 
Berikut di bawah ini gambar diagram rata-rata jumlah helaian daun tanaman bawang daun yang menunjukkan adanya perbedaan dalam setiap perlakuan.

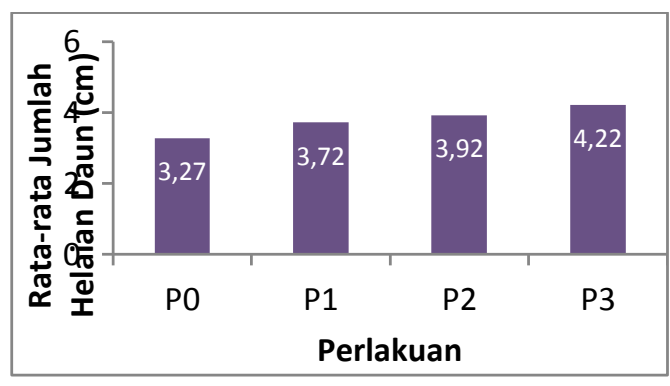

Gambar 3. Diagram Rata-rata Jumlah Helaian Daun Tanaman Bawang Daun pada Minggu Ke 5

Setelah melakukan uji ANAVA satu arah maka hasil analisis data menunjukkan bahwa nilai sig. $0,045<$ 0,05 , yang berarti adanya pengaruh penambahan limbah diapers terhadap jumlah helaian daun bawang daun.

Penambahan limbah diapers pada media tanam dapat meningkatkan pertumbuhan tanaman bawang daun diantaranya, tinggi, diameter batang semu dan jumlah helaian daun. Hal tersebut dapat dilihat pada perlakuan P3 merupakan komposisi yang paling baik, dikarenakan kandungan unsurunsur yang terdapat pada gel diapers semakin tinggi. Unsur-unsur tersebut yang berpengaruh pada pertumbuhan dan perkembangan tanaman bawang daun diantaranya nitrogen, kalium, dan pospor.Menurut Soeparman (2002), urin manusia mengandung 15-19 \% N, $1-2 \% \mathrm{P}$ dan 3-5 \% K. Sehingga hal tersebut akan sangat baik untuk pertumbuhan dan perkembangan tanaman bawang daun, dikarenakan pada perlakuan P3 komposisi limbah diapers yang diberikan tertinggi dibanding perlakuan lainnya.

Menurut Fahmi,dkk (2010), bahwa unsur hara nitrogen dan fosfor merupakan unsur hara yang sangat dibutuhkan oleh tanaman dalam jumlah yang besar, apabila tanaman kekurangan nitrogen pertumbuhannya menjadi lambat dan tanaman menjadi kerdil. Sementara kekurangan fosfor, menyebabkan perakaran tidak berkembang dengan baik dan pertumbuhan tanaman menjadi terhambat.

Limbah diapers yang telah di fermentasi dicampur dengan LCN Pumakkal menambah kandungan unsur-unsur yang dibutuhkan oleh tanaman menjadi lebih tinggi dan mempengaruhi pertumbuhan tanaman. Terutama unsur nitrogen yang dapat merangsang aktivitas meristematik (Choiri, 2015). Oleh sebab itu dengan meningkatnya $\mathrm{N}$ dalam media tanam, semakin meningkat jumlah $\mathrm{N}$ yang diserap oleh tanaman. Sehingga jaringan meristematik pada titik tumbuh batang semakin aktif dan menyebabkan ruas batang akan terbentuk dan tanaman bertambah panjang, dan tanaman akan tumbuh semakin tinggi.

\section{Sumber Belajar Biologi}

Dari hasil penelitian ini dapat diperoleh pengetahuan yang berkaitan dengan materi pertumbuhan dan perkembangan tanaman.Pengetahuan tersebut adalah bahwa adanya pengaruh dari penambahan limbah diapers pada media tanam terhadap meningkatnya pertumbuhan tanaman bawang daun. Hal tersebut dapat dijadikan sumber belajar biologi yang disusun menjadi media cetak berupa brosur edukasi materi pertumbuhan dan perkembangan.

Brosur adalah bahan informasi tertulis mengenai suatu masalah yang disusun secara bersistem atau cetakan yang hanya terdiri atas beberapa halaman dan dilipat tanpa dijilid atau selebaran cetakan yang berisi keterangan singkat tetapi lengkap (Dhamasraya, 2008). 
Brosur edukasi yang telah divalidasi oleh dosen tim ahli memperoleh hasil dalam aspek materi dengan presentase skor sebesar $81 \%$. Sedangkan untuk aspek tampilan atau desain brosur memperoleh presentase skor sebesar $90 \%$.

Berdasarkan hasil validasi brosur dari dosen tim ahli tersebut menyatakan bahwa brosur layak untuk digunakan sebagai sumber belajar biologi materi Pertumbuhan dan Perkembangans erta diharapkan para siswa dapat memperdalam materi tersebut.

\section{KESIMPULAN}

Penambahan limbah diapers $750 \mathrm{~g}$ atau $3 / 4 \mathrm{~kg}$ ke dalam tanah humus sebanyak $250 \mathrm{~g}$ atau $1 / 4 \mathrm{~kg}$ berpengaruh paling baik terhadap pertumbuhan tanaman bawang daun dikarenakan kandungan unsur-unsur hara yangterdapat pada komposisi tersebut paling tinggi dan paling sesuai untuk kebutuhan pertumbuhan tanaman daun bawag, dibandingkan dengan komposisi perlakuan yang lain. Hasil penelitian ini dapat digunakan sebagai sumber belajar biologi yang disusun berupa media cetak yaitu brosur edukasi untuk materi Pertumbuhan dan Perkembangan.

\section{SARAN}

Penelitian mengenai limbah diapers agar dapat dilakukan lebih mendalam mengenai pemanfaatannya untuk pertumbuhan tanaman. Selain itu, hendaknya dapat dijadikan sebagai sumber belajar bioogi materi pertumbuhan dan perkembangan, terutama untuk para peserta didik.

\section{DAFTAR LITERATUR}

Cahyono B. 2005. Teknik Budidaya dan Analisis Usaha Tani Bawang Daun.Yogyakarta. Penerbit Kanisius
Choiri, M. 2005. Pengaruh Pemberian Kombinasi Limbah Jamur Champignon dan Pupuk NPK terhadap ketersediaan $N$, Pertumbuhan dan Hasil Tanaman Sawi (Brassica juncea L) pada Andisol Cangar Malang. Malang : Jurusan Tanah Fakultas Pertanian Universitas Brawijaya.

Dhamasraya, Putra. 2008. Panduan Pengembangan Bahan Ajar. (http://www.dikmenum.go.id/d ataapp/kurikulum/4.\%20perang kat\%20pembelajaran\%20ktsp $\% 20$ sma/05.\%20pengembanga n\%20bahan\%20ajar/panduan\% 20pemgembangan $\% 20$ bahan $\%$ 20ajar.

Fahmi, Arifin., Syamsudin., Sri, Nuryani.

2010

H.U Bostang Radjaguguk.

TheEffect of Interaction of Nitrigen

and Phosporus Nutrients on Maize

(Zea mays L) Grown In

Regosoland Latosol

Soils.Byologic News

Juhri. 2013. Landasan dan Wawasan Pendidikan: Suatu Pendekatan Kompetensi Guru. Metro: Lembaga Penelitian UM Metro Press

Kristianingrum. 2007. Pengembangan Multimedia Pembelajaran Interaktif dengan Macromedia Authorware 7.0 pada Materi Fisika Sekolah Menengah Atas (SMA) Pokok Bahasan Kinematika Gerak Lurus. Skripsi Tidak Diterbitkan. Semarang: Universitas Negeri Semarang.

Muhfahroyin. 2018. Telaah Biologi SMA. Metro.Bandung: Alfabeta 
Sadiman, A.S. 2008. Media

Pendidikan.

Jakarta: PT Raja Grafindo

Persada.

Soeparman., Suparmin. 2002.

Pembuangan Tinja dan Limbah

Cair. Jakarta : Penerbit Buku

Kedokteran.

Sutanto, Agus. 2010. Bioremediasi Limbah Cair Nanas. Malang: UMM Press.

Prastowo A. 2014. Panduan Kreatif Membuat Bahan Ajar Inovatif. Yogyakarta: DIVA Press 
